\title{
A contrastive analysis of rhetorical patterns in English and Spanish expository journal writing: A study for contrastive rhetoricians, teachers of second language composition, and translators
}

Received: 4-Apr-2013 / Accepted: 18-May-2013

Sanchez-Escobar, A. (2012). A contrastive analysis of rhetorical patterns in English and Spanish expository journal writing: A study for contrastive rhetoricians, teachers of second language composition, and translators (2nd ed.). Jaén, Spain: Lengua Española Aplicada a la Enseñanza.186 pages ISBN: 9781479382118

Blackwell (2001) summarizes that A contrastive analysis of rhetorical patterns in English and Spanish expository journal writing analyzes "writing samples from contemporary magazines generally considered by native speakers to contain "good writing"' (as cited in Sanchez-Escobar, 2012, pp. 5-10). In addition, Blackwell (2001) mentions that this book "should be required reading for all of us who write in a second language and who try to teach others to do the same" (p. 9).

Sanchez-Escobar's (2012) purpose for the study is to "analyze and compare the structure of English and Spanish paragraphs, as well as that of complete essays written by professional writers" (p. 15). Without a doubt, A contrastive analysis of rhetorical patterns in English and Spanish expository journal writing emphasizes the importance of having sentences serving a purpose in expository writing with the use of logic and coherence (Sanchez-Escobar, 2012, p. 87).

In A contrastive analysis of rhetorical patterns in English and Spanish expository journal writing, Professor Sanchez-Escobar (2012) includes a plethora of terminology for contrastive rhetoric and its specific component, such as "subject, audience, [and] point of view" (p. 11). Smith (2007) agrees with Sanchez-Escobar (2012) that "writing is a process that helps students blend, reconcile, and gain personal ownership of new knowledge" (p. 26). Furthermore, Sanchez-Escobar (2012) tries to ensue this importance by mentioning that "to be effective, writers have to learn what is expected of them within their own culture" (p. 12). Charity Hudley \& Mallinson (2011), in conjunction with Sanchez-Escobar (2012), declare that "language is an essential component of a student's culture and identity" (p. vii). Moreover, Sanchez-Escobar (2012) corroborates with Charity Hudley \& Mallinson (2011) in answering if the differences in standard and nonstandard forms of English and how this alters a teachers' perception of student writing.

This study explicitly utilizes a variety of methods (Christensen, 1963; Karrfalt, 1966; \& D'Angelo, 1976) to analyze English and Spanish writing of authors in contemporary magazines. Christensen's method (1963) provides the "likeness or evidence of coordination between" (as cited in Sanchez-Escobar, 2012 , p. 87) sentences in relation to the topic sentence. Specifically, the topic sentence is the first sentence in a section and should state what the rest of the paragraph is going to be about. Namely, these supporting sentences are to present coordination or subordination (Sanchez-Escobar, 2012). That is to say that, sentences have different levels of importance when compared to the topic sentence. Equally important, Karrfalt (1966) goes beyond Christensen's (1963) explanation of a paragraph to what he calls the "structural addition by completion" (as cited in Sanchez-Escobar, 2012, p. 90). In other words, Karrfalt (1966) believes that sentences are more than just coordination and subordination. Likewise, D'Angelo (1976) further distinguishes

Colomb. Appl. Linguist. J. 
"both the semantic and the grammatical levels in the subordinate and coordinate sequences" (as cited in Sanchez-Escobar, 2012, p. 93). In brief, Smith (2007) simplifies this as the topic sentence, major details, and minor details respectively (p.98).

A contrastive analysis of rhetorical patterns in English and Spanish expository journal writing utilizes a mixed methods approach to compare and contrast English and Spanish paragraphs found in contemporary magazines. Quantitatively, all sentences in a paragraph were counted to provide a sum. These sums were then calculated to determine how the number of sentences and paragraphs, in both English and Spanish, were compared to the number of words and the number of sentences in all writings.

This mixed methods approach is used to "analyze writing samples from contemporary magazines" (Sanchez-Escobar, 2012, p. 8); however, the title of this book suggests contrastive rhetoricians, teachers of second language composition, and translators as its audience. The audience was not clearly addressed throughout. A contrastive analysis of rhetorical patterns in English and Spanish expository journal writing, for example, addresses the implication to language teaching in just seven paragraphs. Even then, this address to teachers of second language learners is asking to consider these suggestions only in relation to "advanced Spanish-speakers" (SanchezEscobar, 2012, p. 147).

Sanchez-Escobar (2012) is ambiguous when mentioning that "an increasing amount of research on coherence has come from the field of text linguistics" (p. 83). Definitely, this research can serve as a leeway for further discussion on specific language variations in regards to linguistics. It would be interesting to see how culture and nonstandard forms of English were seen in a different variety of writings, rather than just published authors.

Ironically enough, Sanchez-Escobar (2012) presented the information in a way that undermines his overall theme: coherence. Rather than presenting a term and its definition, for example, he concentrated on introducing an author and his or her contributions to a term rather than constructing a working definition for the term and using a variety of authors to supplement it.

Considering A contrastive analysis of rhetorical patterns in English and Spanish expository journal writing from a teacher's perspective, the reasoning for students using their culture as part of their writing was not clear. As previously mentioned, it is understandable that students will write on what they know and have experienced before; however, Sanchez-Escobar (2012) mentioned this fact in his introduction and failed to elaborate upon it. As previously mentioned, if A contrastive analysis of rhetorical patterns in English and Spanish expository journal writing was written for contrastive rhetoricians, teachers of second language composition, and translators, this fact was not prevalent throughout.

Being an instructor for a university, I have seen a variety of styles from native English and Spanish speakers. Throughout this endeavor, I have seen my student's metalinguistic awareness abilities during their construction of essays. Overall, whether my students are constructing essays or paragraphs, I believe it is more important for them to understand the purpose for each sentence, rather than concentrating on how much they are writing. In other words, I believe that quality, rather than quantity, is important

\section{Works Cited}

Charity Hudley, A., \& Mallinson, C. (2011). Understanding English language variation in U.S. schools. New York: Teachers College Press.

Smith, B. (2007). The reader's handbook: Reading strategies for college and everyday life (3rd ed.). New York: Pearson.

Hilda Moreno Adjunct Instructor of Spanish, Department of Language and Literature, Texas A\&M University-Kingsville, USA Hilda. Garcia@tamuk.edu 